Original Research Paper

\title{
Modern Propulsions for Aerospace-Part II
}

\author{
${ }^{1}$ Relly Victoria Virgil Petrescu, ${ }^{2}$ Raffaella Aversa, ${ }^{3}$ Bilal Akash, \\ ${ }^{4}$ Ronald Bucinell, ${ }^{5}$ Juan Corchado, \\ ${ }^{2}$ Antonio Apicella and ${ }^{1}$ Florian Ion Tiberiu Petrescu \\ ${ }^{1}$ ARoTMM-IFToMM, Bucharest Polytechnic University, Bucharest, (CE), Romania \\ ${ }^{2}$ Advanced Material Lab, Department of Architecture and Industrial Design, \\ Second University of Naples, 81031 Aversa (CE), Italy \\ ${ }^{3}$ Dean of School of Graduate Studies and Research, American University of Ras Al Khaimah, UAE \\ ${ }^{4}$ Union College, USA \\ ${ }^{5}$ University of Salamanca, Spain
}

Article history

Received: 18-04-2017

Revised: 22-04-2017

Accepted: 25-04-2017

Corresponding Author: Florian Ion Tiberiu Petrescu ARoTMM-IFToMM, Bucharest Polytechnic University, Bucharest, (CE), Romania E-mail: scipub02@gmail.com

\begin{abstract}
Speaking about a new engine ionic means to speak about a new aircraft. The paper presents in a short time the actual engines ion chambers (called the ion thrusters) and other new ionic motors proposed by the authors. The engine (ionic propulsion unit of ions, that accelerates the positive ions through a potential difference) is approximately ten times more efficient than classic system based on combustion. We can further improve the efficiency of the 10-50 times in the case in which is used the pulses of positive ions accelerated in a cyclotron mounted on the ship; efficiency may increase with ease of a thousand times in the case in which the positive ions will be accelerate in a synchrotron high energy, synchrocyclotron or isochronous cyclotron $(1-100 \mathrm{GeV})$. For this, the great classic synchrotron is reduced to a surface-ring (magnetic core). The future (ionic) engine will have a circular particle binding (energy high or very high speed). Thus we can increase the speed and autonomy of the vessel, using a smaller quantity of fuel. It can be used a radiation synchrotron (synchrotron high intensity), with X-ray or gamma radiation. In this case, will result in a beam engine with the wiring (not an ionic engine), which will use only the power (energy, which may be solar energy, nuclear energy, or a combination) and so we will eliminate the fuel. It is suggested to use a powerful LINAC at the outlet of the synchrotron (especially when one accelerates the electron beam) in order not to lose power by photons of the emission premature. With a new ionic engine practically builds a brand new aircraft that can move through the water and air with the same ease. This new aircraft will be able to expedite directly, without an engine with the additional combustion and without the gravity assistance.
\end{abstract}

Keywords: Spacecraft Propulsion, Chemical Rockets, Jet Engines, Satellites, Electric Propulsion, Ionic Engine, Beam Engine, Ion Thrusters, LINAC, Cyclotron, Synchrotron High Intensity, Magnetic Core, Gridded Electrostatic Ion Thrusters, Field Emission Electric Propulsion (FEEP), Pulsed Inductive Thrusters (PIT), Magnetoplasmadynamic (MPD), Electrodeless Plasma Thrusters, The Hipep Engine

\section{Introduction}

Propulsion, on an aircraft, is obtained by creating a force, called thrust, which results from the acceleration of a mass of air by a propeller (driven by a piston engine or a turboshaft engine), or by the combustion of an air/fuel mixture (turbojet engine or rocket engine).

The powertrain, which usually includes one, two or four engines, is one of the main components of the aircraft. This characteristic is often used to classify 
aircraft: Mono, bi or quadrimo, bi or quadritoprop, mono, bi or quadrijet.

The single-flow turbojet engine, which appeared in the Second World War, has given rise to turboprop and turbofan derivatives (turbofan engines) used on almost all heavy or fast-moving aircraft (less than $800 \mathrm{~km} / \mathrm{h}$ ), civilian and military, as well as on fighter jets. There is also a hybrid between these two systems called "propfan".

At the beginning of the 21 st century, the propellerdriven piston engine remained the most widely used system in almost all light aircraft (ULMs, planes and light helicopters). It was supplanted by the turbine engine for heavy or rapid helicopters, civil and military. The thrusters are classified below according to their dilution ratio: The proportion between the thrust resulting from the acceleration of cold air and hot air. This classification has the merit of showing that a single principle is used for propulsion, even if it is declined in different technologies. That is why this article includes the propeller-driven motor, the ramjet and the pulsoreactor, which, although they have not undergone significant development, are part of the continuity of the presentation.

Speaking about a new engine ionic, means to speak about a new aircraft. The paper presents in a short time the actual engines ion chambers (called the ion thrusters) and other new ionic motors proposed by the authors. The engine (ionic propulsion unit of ions, that accelerates the positive ions through a potential difference) is approximately ten times more efficient than classic system based on combustion. We can further improve the efficiency of the 10-50 times in the case in which is used the pulses of positive ions accelerated in a cyclotron mounted on the ship; efficiency may increase with ease of a thousand times in the case in which the positive ions will be accelerate in a synchrotron high energy, synchrocyclotron or isochronous cyclotron (1-100 GeV). For this, the great classic synchrotron is reduced to a surface-ring (magnetic core). The future (ionic) engine will have a circular particle binding (energy high or very high speed). Thus we can increase the speed and autonomy of the vessel, using a smaller quantity of fuel. It can be used a radiation synchrotron (synchrotron high intensity), with X-ray or gamma radiation. In this case, will result in a beam engine with the wiring (not an ionic engine), which will use only the power (energy, which may be solar energy, nuclear energy, or a combination) and so we will eliminate the fuel. It is suggested to use a powerful LINAC at the outlet of the synchrotron (especially when one accelerates the electron beam) in order not to lose power by photons of the emission premature. With a new ionic engine practically builds a brand new aircraft that can move through the water and air with the same ease. This new aircraft will be able to expedite directly, without an engine with the additional combustion and without the gravity assistance (Petrescu and Petrescu, 2011; 2012; 2013a; 2013b; 2013c).

\section{History}

Hermann Oberth father romanian-german (Romanian citizen by German ethnicity) of missiles, has an inheritance joint venture. On the one hand, he developed the $\mathrm{V}-2$ rockets for nazi Germany during the World War II. On the other hand, his ideas, rejected as not plausible at that time (when presented them as part of its allegations of doctoral), had opened the way for the development of the rockets and later helped up-to-theminute in the United States of America in space.

\section{Her Youth}

Hermann Oberth Julius was born in June 25 1894, from parents speakers of German and Romanian from Transilvania (a province in Romania). Inspired by the novel science fiction of Jules Verne, "from earth to moon", Oberth leans early to study mathematics, of which he knew that finally he need. At the age of 14 years, Oberth has designed the concept of a rocket back down, which would be the use of exhaust gas expelled to propel.

The son of a doctor, Oberth has participated at the University of Munich, in 1912 to study medicine. During the first world war, he served as a doctor in the army Austro-Hungarian occupation, where he quickly realized that he did not want to be a doctor. In 1917, he suggested the development of missiles long range of action with the liquid fuel for the German army, which has immediately rejected the idea. He studied, also, the feasibility of a rocket with several steps to the waiver gears who were useless.

Oberth married Mathilde Hummel on 6 July 1918. The couple has had four children, two of whom were killed during the second world war.

\section{The Theory of the Missile Dismissed}

At the end of the first world war, Oberth returned to Germany to participate at the University of Heidelberg, studying physical, rather than medicine. In 1922, he presented dissertation based on a design by the missile. It has been rejected by the scientists gophers then.

It fiercely, he has published his theories as a pamphlet entitled "Die Rakete zu den Planetenräumen" ("by missile in space planetary drive"), which has extended it subsequently at 429 pages. The work not only of the mathematical demonstrated the ability of a rocket leaving the orbiting the earth, but also explored the theory that finally they will be able to operate in a vacuum, where they would be able to travel even faster than their own exhaust (When Robert Goddard has proposed in an independent manner, the idea that a missile would be able to maintain the tractive force in a vacuum in the year 1920, he was faced with a public ridiculing.).

Oberth also has reached the problems with respect to the potential effects of the traveling in the space on the human body, as well as the ability to launch satellites orbit. 
The work of the Oberth have attracted a lot of attention from the community of missiles, inspiring a young Werhner von Braun to apply in math and physics in order to better understand the equations. A few years later von Braun introduced Oberth in the "German Space Travel Society", where later Oberth become the president.

\section{The Years of War}

Oberth has acquired the German citizenship in 1940. During the second world war, Oberth joined to the former pupil, von Braun to produce the famous missiles V-2 for Germany: 27,000 pounds (12250 kg) missile could carry over $3,500 \mathrm{~km}$. So the missile have rained over Great Britain during the second world war, killing over 3,000 persons and injuries to other tens of thousands.

Before the end of the war, Oberth has left the project V-2 to develop rockets solid fuel anti-airline. After the second world war, Oberth served in the quality of the consultant of missiles in Switzerland and has worked to the development of the outboard motors for air missiles for marina Italian.

In 1955, Oberth has moved to the United States to work again with the von Braun, this time with respect to the development of missiles capable of reaching the space for the US army. Their work resulted in the development of the champion Saturn V, who has carried people per month. Has not adapted to the American life, where he remained only for a period of three years, after which he will be permanently withdrawn in the West Germany in 1958 (it would be desirable to return to the homeland of his native, Romania, but he could not because of the new communist regime installed in the whole Eastern Europe; moreover even Germany was divided into two after the second world war, having regard and an area Eastern Europe, the communist regime, which Oberth avoided it permanent).

After his withdrawal, Oberth has continued to work at the theoretical studies by the missile. He died on 29 December 1989, in Nuremburg, West Germany, immediately after the fall of the Berlin Wall (symbol of the beginning of the end of the age and the experiment of communism).

Although Oberth has developed many of the theories of the early his at the same time as the American engineer Robert Goddard and man of science rus Konstantin Tsiolkovsky, there is no clear evidence that the last two were based on a different work of him (the oldest). As such, all three men are considered together as parents missiles.

\section{Materials and Methods}

An ion thruster is a form of propulsion diagram used for the propulsion of the spatial vessels which creates the tractive force by accelerating ions. Ion thruster is characterized by the way in which they accelerates the ions by use of force be electrostatic or electromagnetically. Propulsions by ion electrostatic discharge use force Coulomb and accelerates the ions in the direction of the electric field strength. Electromagnetic propulsions of ions use of force Lorentz to accelerate the ions. Please note that the term 'propulsion unit ion" denotes frequently outboard of ions electrostatic discharge or grid, only.

Pushrod created in ion thruster is very small in comparison with the rocket conventional chemical, but an impulse to the very high, or fuel efficiency which shall be obtained (Petrescu and Petrescu, 2011, 2012, 2013a, 2013b, 2013c).

Because of the needs of their power relatively high, taking into account the specific power of power supplies, as well as the requirement of a vacuum environment of other ionizing particle, propulsion the tractive force of ions in the present time is only possible in the outer space.

The first experiments with tappets of ions have been carried out by Robert Goddard at Clark College 19161917 (Goddard, 1916). The technique has been recommended for conditions close to the vacuum pump at high altitude, but the tractive force has been demonstrated with streams of ionized air to atmospheric pressure. The idea has appeared again in Hermann Oberth of "Wegezur Raumschiffahrt" (Ways of Spaceflight), published in 1923 (Hermann Oberth, From Wikipedia, Oberth, 1955).

A tappet of ions work has been built by Harold R. Kaufman in 1959 installations at NASA Glenn (Kaufman, 1959). It was similar to the design of the general of a tappet incised electrostatic ion with mercury as fuel or. Future comercial applications tests of the engine followed in 1960 and in 1964 the engine has been sent in a future comercial applications flight on board electrical Orizont Test 1 (SERT 1). It has been operating successfully planned for 31 minutes before you are ready to fall back on the ground (Petrescu and Petrescu, 2011; 2012; 2013a; 2013b; 2013c).

Center researcher Harold Kaufman has the rare distinction of inventing an experimental spaceflight hardware system that has not only been demonstrated in testing but is being flown in space today. In the early 1960s Kaufman developed the electron bombardment ion thruster. All ensuing U.S. ion propulsion systems have been derived from his original Kaufman thruster and electric propulsion remains one of the center's core competencies. After retiring from NASA, Dr. Kaufman adapted the technology for a number of Earth applications and developed a gridless thruster that has become another industry standard.

Kaufman was born in Audobon, Iowa, in 1926 but was raised in Evanston, Illinois. He was trained as an electrical engineer in the Navy during World War II. After the war, however, he decided to pursue a mechanical engineering degree at Northwestern 
University. He joined the NACA Lewis Research Center shortly after graduating in 1951, initially working on aeropropulsion issues such as afterburner cooling and the experimental use of liquid hydrogen in jet engines.

Following the Soviet Union's launch of Sputnik in 1957, the NACA became a part of the new NASA space agency and the center reorganized to focus on spacerelated issues. Electric propulsion involved ion thrusters, which create charged plasma and expel it as thrust. The concept was not new, but it had yet to be demonstrated when NASA Lewis took up the effort in 1958. Lewis devised mission applications for such a thruster, began constructing vacuum test facilities and formed the Electromagnetic Propulsion Division to explore a range of different types of electric propulsion for spaceflight (Petrescu, 2009).

In 1958 Kaufman was reassigned to the new Electromagnetic Propulsion Division. He was initially instructed to design a thruster using a Manfred Von Ardenne-designed duoplasmatron but quickly realized that it was impractical. He began work on his own duoplasmatron, which was similar in nature, but used different proportions. Kaufman spent the next year studying plasma physics and ways to produce high electrical currents at low voltage. After some trial and error with the Lewis Machine Shop, Kaufman decided to design the thruster himself. The electronic bombardment thruster (Kaufman thruster) emerged.

Kaufman's engine vaporized liquid mercury, which was then bombarded by electrons to create more electrons and ions. A negatively charged electric field and a positively charged screen drew the ions rearward and out of the engine as thrust. The thruster was tested extensively in Lewis vacuum facilities with excellent results.

In 1960 Kaufman and his colleagues began planning the Space Electric Rocket Test (SERT I) to test the thruster in space. The SERT I spacecraft, which was launched in July 1964, also included an alternative style thruster designed at the NASA Marshall Space Flight Center. Kaufman's thruster operated for over $30 \mathrm{~min}$, but the Marshall engine failed to activate. SERT I provided the first demonstration of electric propulsion in space.

In 1964 Kaufman was named head of the Ion Physics Branch and began planning a second space demonstration of his thruster, SERT II. SERT II employed two solar-powered mercury ion bombardment thrusters. Lewis subjected the thrusters to an array of tests, including long-duration performance. Although SERT II's initial mission, which was launched in February 1970, did not meet its intended 6-month duration, engineers were able to restart the engines in 1973. They then were able to operate the thrusters for eight years and restart them hundreds of times.

During this period the Electromagnetic Propulsion Division not only improved the ion acceleration, generation, efficiency and life expectancy for Kaufman's thruster, but developed alternative electric thrusters. Kaufman was named assistant chief of the division in 1968 and earned a Ph.D. at Colorado State University (CSU) in 1971. Dr. Kaufman and his thruster were widely recognized during this period. The American Institute of Aeronautics and Astronautics (AIAA) awarded him the James H. Wyld Propulsion Award in 1969, the thruster won an IR 100 award (predecessor to the R\&D 100 Awards) in 1970 and Kaufman received NASA's Exceptional Service Award in 1971.

NASA's budget was rapidly decreasing in the late 1960s and early 1970s, particularly for programs with long development periods-such as electric propulsion. The Electromagnetic Propulsion Division was disbanded during a 1972 reorganization. After serving two years as Assistant Chief of the new Spacecraft Technology Division, in which electric propulsion was just one of several branches, Dr. Kaufman retired in June 1974 with 23 years of NASA experience.

Dr. Kaufman subsequently accepted a faculty post in the Physics and Mechanical Engineering departments at CSU and returned to research (Petrescu, 2009).

Gridded electrostatic ion thrusters (ionic) normally are using xenon gas. This gas has no charge and ionized is by the bombing with the electron beam in the energy sector. These electrons can be supplied from a filament Hot Cathode and accelerated in the field of the electric cathode side falling to the anode (type engine Kaufman ionic). Alternatively, the electrons can be accelerated by the electric field induced rocking by a magnetic field alternate a coil, which results in a discharge of stand-alone and omits any cathode (radio frequency ion propulsion unit).

The ions positive charge is extracted through a system of extraction apparatus consisting of 2 or 3 multiple grilles apertures. After the entry into the net system by means of the shell of plasma ions are accelerated due to the difference of potential between the first and second grid (called screen and grid accelerator depressed) for energy final ions typically $1-2 \mathrm{keV}$, thus generating draft force.

Thrusters ion emit a beam of Positive Ions Xenon only loaded. To avoid loading of the operation of the space ship another cathode, located in the vicinity of the engine, issue additional electron (in fact the current of electrons is the same as the current of ions) in the wiring ions. This prevents, also the beam of ions from the return to the spaceship and cancellation, thus draft force (Petrescu, 2009).

Field Emission Electric Propulsion (FEEP) thrusters use a very simple system for the acceleration of ions of metal liquid to create the draft force. Most models will use either caesium chloride or indium as an agent is lowered. The design is composed of a fuel tank than that stores liquid metal, a very small, allowing the liquid flows through and then the ring accelerator. Caesium and indium are used because of the high weights, atomic 
potential low ionization and points of low melting. After the liquid metal reaches the inside of the slot in the transmitter, an electric field applied between the master cylinder and the accelerator ring determines the liquid metal to become unstable and ionization. This creates a positive ion, which can then be accelerated in the electric field created by the transmitter and the ring accelerator. These charged ions are positive then neutralized by an external source of electrons in order to prevent the loading of the hull of the vessel of space (Petrescu, 2009).

Pulsed Inductive Thrusters (PIT) use a system touch the pushrod (instead of one pushrod continue) and have the ability to run on power levels in the order of the Megawatts (MW). The pits consist of a large coil encircling which a tube in the shape of a cone, issuing the gas is lowered. Ammonia is the gas used in the usual manner in engines pit. For each pulse of the pushrod pit yes, a levy high build first in a group of capacitors behind the coil and is then released. This creates a current which is made to move in a circular motion. The current then creates a magnetic field in the direction of the eccentricity outwards (BR), which then creates a current in the gas of ammonia, which has just been released in the opposite direction of the current initially. This current ionizes opposed the ammonia and these charged ions are positive accelerated away from the engine pit due to the changeover electric field strength with the magnetic field $\mathrm{Br}$, which are due to Lorentz Force (Petrescu, 2009).

Magneto Plasma Dynamic (MPD) thrusters and craft Lithium Lorentz Force Accelerator (LiLFA) use approximately the same idea about the building of the propulsion unit LiLFA off for the propulsion unit of the MPD. Hydrogen, argon, ammonia and nitrogen gas can be used as fuel. The gas enters the first in the main room where it is ionized in the plasma of the electric field between the anode and cathode. This plasma lead then electricity between the anode and cathode. This new current creates a magnetic field around the cathode side which crosses with the electric field, so speeding up the plasma due to Lorentz. LiLFA propulsion unit uses the same general idea of propulsion unit MPD except for two main differences. The first difference consists in the fact that LiLFA vapor uses the lithium, which has the advantage of being able to be stored in the form of a solid. The other difference is that the cathode material is replaced with the more rods for small cathode packed in a cathode ray tube hollow bolt. Cathode material of the Propulsion Unit MPD is slightly corroded due to contact with the plasma. In the propulsion unit LiLFA vapors of lithium is injected into the hollow-cathode and is not ionized in the form of the plasma/corrode the rods its cathode, until it comes out of the tube. Then Plasma is accelerated using the same Lorentz Force (Petrescu, 2009).

Electrodeless Plasma Thrusters have two unique features, removal of the electrodes anode and cathode and the ability to slow down the engine. Removal of the electrodes take away the factor by erosion which limits the duration of life on other engines of ions. neutral gas is first ionized by electromagnetic waves and then transferred to another room, where is accelerated by an electric field and oscillating magnetic, also known under the name of ponderomotive force. This separation of the stage of ion chamber and acceleration allow to the engine the ability to pinch the speed of fuel flow, which changes when the amplitude of the pushrod and the values of the specific impulse (Petrescu, 2009).

\section{The Hipep Engine (The HIgh Power Electric Propulsion ion engine)}

A powerful new system of propulsion of ions has been successfully ground-to-tested by NASA. The engine ion process with high electrical power of propulsion marks the first milestone measurable" for ambitious 3 billion \$ Project Prometeu, says director Alan Newhouse.

The engine HiPEP is the first technology of propulsion tested with potential power and longevity for spacecraft the tractive force in the extent to which the Jupiter without the assistance of the gravitational pull on other planets.

These assist involves parking maneuvers slingshot around the planets and can significantly increases the speed of the craft. But they need some alignments specific planetary, which means given by the appropriate launch are scarce.

In contrast, a probe propelled by an engine HiPEP would be able to launch at any time. An Objective of the project Prometeu as the initiatives of nuclear systems, is to launch a spaceship to Jupiter, by 2011. The flight will last for at least eight years.

The key elements of the engine HiPEP are a high speed of the exhaust, a method based on a microwave for the production of ions which carry out more than the existing technologies and a design rectangular, which may be more easily scaled than those.

Spaceships are constructed with engines of ions, rather than the engines burning fuel for the rockets. This is due to the fact that the engines of ions produces more power for a certain amount of the agent of the means of propulsion and provide a smooth output, rather than intermittent outbursts.

"Jupiter is such a target far away. Using a chemical system, simply could not do this," Says John Foster, one of the main creators of the motor of the NASA Glenn Research Center from Cleveland, Ohio.

The engine HiPEP differ from engines with the previous ion, such as the fact that the supply to the Deep Space a mission NASA, because the cupric ions bulbs are produced using a combination of microwave ovens and magnets spinning. Previously, the electrons required have been supplied by a cathode. The use of microwave 
ovens significantly reduces wear on the engine by avoiding any contact between the ions of excess speed and the source of the electron beam.

A spaceship Japanese-repelling asteroid is already using the technology based on the microwave oven to produce ions, but Hayabusa uses a small business, which could not produce enough energy to flew toward Jupiter. The engine HiPEP is currently capable of 12 kilowatts power, but the production will be stimulated to at least $50 \mathrm{~kW}$ for his mission to Jupiter. The cross-section rectangular HiPEP engine will do this easier since can be extended along one of its sides. A circular engine should be rebuilt, says NASA (Petrescu and Petrescu, 2011; 2012; 2013a; 2013b; 2013c).

However, other researchers at the NASA Jet Propulsion Laboratory in Pasadena, California, working on an engine with ions of great power cylindrical, also for the project or at least it was. But Newhouse finds that building a system of propulsion powerful, long time is just one of the parts that we need to get to Jupiter". The electrical energy for the engine of ions is scheduled to come from the reactor of nuclear fission on board. That part of the project Prometeu is only the beginning with the considerations of safety, miniaturization reactor and the identity of the fuel, they need to be clarified (Petrescu, 2009).

\section{Results}

Through this work the authors propose a new engine of pulses that works with the wiring or (ionic beam) ionic pulses (Petrescu, 2009). With a new ionic engine one can build a new aircraft (a new ship). The main feature of this type of motor is high power (energy) that accelerates the greater energy in the circular accelerators, in Linear Accelerators Modern (LINAC), or both. Can be used accelerators similar to accelerators of physics (static synchrotron, synchrocyclotron or isochronous cyclotron).

The ionic engine (propulsion unit of ions, that accelerates the positive ions through a potential difference) is approximately ten times more efficient than classic system based on combustion. We can further improve the efficiency of the 10-50 times in the case of using the positive ions accelerated in a cyclotron mounted on the ship; efficiency may increase with ease of a thousand times in the case in which the positive ions will be accelerated in a synchrotron high energy, synchrocyclotron or cyclotron isochronous (1-100 GeV).

The future (ionic) engine will have to apply a circular accelerator the particle filter (energy high or very high, see Fig. 1). Sure that the difficulties will appear from design, but they must be resolved step by step. Thus we can increase the speed and autonomy of the vessel, using a smaller quantity of fuel.

It can be used by the radiation synchrotron (synchrotron, beams high intensity), such as high- intensity (with X-ray or gamma-ray) radiation. In this case, it would be an engine harness (not an ionic engine), (Petrescu and Petrescu, 2011; 2012; 2013a; 2013b; 2013c). A linear accelerator of the particle filter (also called LINAC) is an electrical device to accelerate subatomic particles. This type of accelerator the particle filter has many applications. Is used recently said that from an injector in a synchrotron less power over a dedicated lab physics experimental particles. In this, the great classic synchrotron is reduced to a surface-ring (magnetic core), (Petrescu, 2009).

The design of an LINAC depends on the type of particle filter, which is accelerated: The electron beam protons or ions. It is suggested to use a powerful LINAC at the outlet of the synchrotron (especially when one accelerates the electrons) is not wasting energy photons of premature emission (Fig. 1 and 2). One can use a LINAC in entry into synchrotron and another one at the output (Fig. 1 and 2). To use a LINAC low input (between him and synchrotron) one put it on a speed circuit of the additional, in a form of a stadium (Fig. 1 and 2), (Petrescu, 2009; Petrescu and Calautit, 2016; Petrescu et al., 2016).

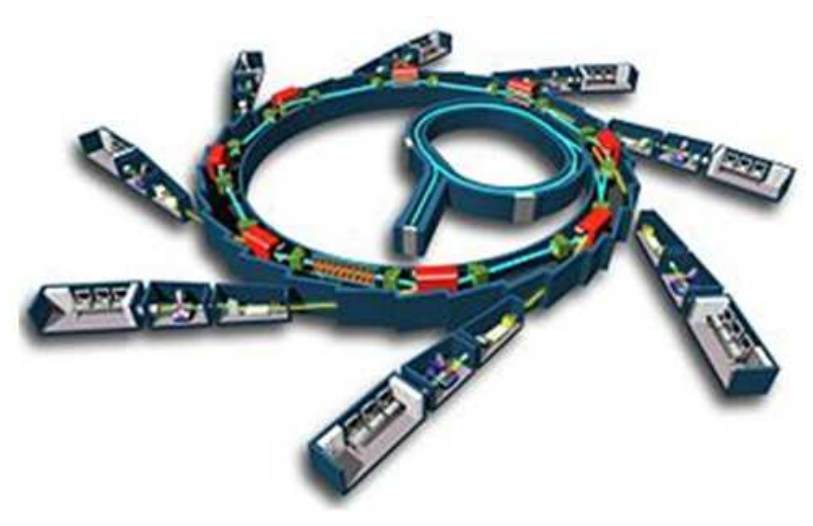

Fig. 1. A high energy synchrotron schema

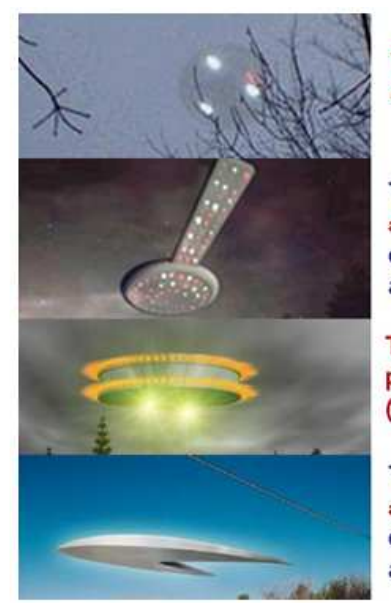

This ship has a circular particle accelerator (a synchrotron)

This ship has first a circular particle accelerator (a synchrotron), and at the end a big linear particle accelerator (a big LINAC)

This ship has two circular particle accelerators (two synchrotrons)

This ship has first a circular particle accelerator (a synchrotron), and at the end two big linear particle accelerators (two big LINAC)

Fig. 2. Some flying synchrotron prototypes 


\section{Discussion}

An ion thruster is a form of propulsion diagram used for the propulsion of the spatial vessels which creates the tractive force by accelerating ions. Ion thruster is characterized by the way in which they accelerates the ions by use of force be electrostatic or electromagnetically.

Gridded electrostatic ion thrusters commonly utilize xenon gas. This gas has no charge and is ionized by bombarding it with energetic electrons. These electrons can be provided from a hot cathode filament and accelerated in the electrical field of the cathode fall to the anode (Kaufman type ion thruster). Alternatively, the electrons can be accelerated by the oscillating electric field induced by an alternating magnetic field of a coil, which results in a self-sustaining discharge and omits any cathode (radiofrequency ion thruster).

Field Emission Electric Propulsion (FEEP) thrusters use a very simple system for the acceleration of ions of metal liquid to create the draft force. Most models will use either caesium chloride or indium as an agent is lowered. The design is composed of a fuel tank than that stores liquid metal, a very small, allowing the liquid flows through and then the ring accelerator.

Pulsed Inductive Thrusters (PIT) use a system touch the pushrod (instead of one pushrod continue) and have the ability to run on power levels in the order of the Megawatts (MW). The pits consist of a large coil encircling which a tube in the shape of a cone, issuing the gas is lowered. Ammonia is the gas used in the usual manner in engines pit. For each pulse of the pushrod pit yes, a levy high build first in a group of capacitors behind the coil and is then released. This creates a current which is made to move in a circular motion.

Magneto Plasma Dynamic (MPD) thrusters and craft Lithium Lorentz Force Accelerator (LiLFA) use approximately the same idea about the building of the propulsion unit LiLFA off for the propulsion unit of the MPD. Hydrogen, argon, ammonia and nitrogen gas can be used as fuel. The gas enters the first in the main room where it is ionized in the plasma of the electric field between the anode and cathode. This plasma lead then electricity between the anode and cathode. This new current creates a magnetic field around the cathode side which crosses with the electric field, so speeding up the plasma due to Lorentz. LiLFA propulsion unit uses the same general idea of propulsion unit MPD except for two main differences.

Electrodeless Plasma Thrusters have two unique features, removal of the electrodes anode and cathode and the ability to slow down the engine. Removal of the electrodes take away the factor by erosion which limits the duration of life on other engines of ions. neutral gas is first ionized by electromagnetic waves and then transferred to another room, where is accelerated by an electric field and oscillating magnetic, also known under the name of ponderomotive force. This separation of the stage of ion chamber and acceleration allow to the engine the ability to pinch the speed of fuel flow, which changes when the amplitude of the pushrod and the values of the specific impulse.

A powerful new system of propulsion of ions has been successfully ground-to-tested by NASA. The engine ion process with high electrical power of propulsion marks the first milestone measurable" for ambitious 3 billion $\$$ Project Prometeu, says director Alan Newhouse.

The engine HiPEP is the first technology of propulsion tested with potential power and longevity for spacecraft the tractive force in the extent to which the Jupiter without the assistance of the gravitational pull on other planets.

These assist involves parking maneuvers slingshot around the planets and can significantly increases the speed of the craft. But they need some alignments specific planetary, which means given by the appropriate launch are scarce.

In contrast, a probe propelled by an engine HiPEP would be able to launch at any time. An Objective of the project Prometeu as the initiatives of nuclear systems, is to launch a spaceship to Jupiter, by 2011. The flight will last for at least eight years.

The key elements of the engine HiPEP are a high speed of the exhaust, a method based on a microwave for the production of ions which carry out more than the existing technologies and a design rectangular, which may be more easily scaled than those.

Spaceships are constructed with engines of ions, rather than the engines burning fuel for the rockets. This is due to the fact that the engines of ions produces more power for a certain amount of the agent of the means of propulsion and provide a smooth output, rather than intermittent outbursts.

"Jupiter is such a target far away. Using a chemical system, simply could not do this," Says John Foster, one of the main creators of the motor of the NASA Glenn Research Center from Cleveland, Ohio.

The engine HiPEP differ from engines with the previous ion, such as the fact that the supply to the Deep Space a mission NASA, because the cupric ions bulbs are produced using a combination of microwave ovens and magnets spinning. Previously, the electrons required have been supplied by a cathode. The use of microwave ovens significantly reduces wear on the engine by avoiding any contact between the ions of excess speed and the source of the electron beam.

A spaceship Japanese-repelling asteroid is already using the technology based on the microwave oven to produce ions, but Hayabusa uses a small business, which could not produce enough energy to flew toward Jupiter. The engine HiPEP is currently capable of 12 kilowatts power, but the production will be stimulated to at least $50 \mathrm{~kW}$ for his mission to Jupiter. The cross-section rectangular HiPEP engine will do this easier since can be 
extended along one of its sides. A circular engine should be rebuilt, says NASA (Petrescu and Petrescu, 2011; 2012; 2013a; 2013b; 2013c).

However, other researchers at the NASA Jet Propulsion Laboratory in Pasadena, California, working on an engine with ions of great power cylindrical, also for the project or at least it was. But Newhouse finds that building a system of propulsion powerful, long time is just one of the parts that we need to get to Jupiter". The electrical energy for the engine of ions is scheduled to come from the reactor of nuclear fission on board. That part of the project Prometeu is only the beginning with the considerations of safety, miniaturization reactor and the identity of the fuel, they need to be clarified (Petrescu, 2009).

Very important are and materials used today (Aversa et al., 2017a; 2017b; 2017c; 2017d; 2017e; 2016a; 2016b; 2016c; 2016d; 2016e; 2016f; 2016g; 2016h; 2016i; 2016j; 2016k; 2016l; 2016m; 2016n; 2016o).

\section{Conclusion}

The ionic engine (the tappet ion) has 2 major advantages (a) and 2 disadvantages (b), in comparison with the chemical propulsion; (A) impulse and energy per unit of fuel used are much higher; 1-momentum has increased generates a speed higher (speed, so that we can go down on the greater distances in a short time), 2-energy high decreases the fuel consumption and to increase the autonomy of the ship; (b) that generates a force and the accelerator pedal are very small; we can't defeat the forces of resistance to the accommodation through the atmosphere and have no chance to exceed the gravitational forces-the ship will not let a planet (or to fall on it) using the propulsion unit of ions (it is necessary a supplementary engine). The acceleration of the ship, the vacuum pump is possible, but only with the accelerator pedal very low.

Increase more than the energy (and also the impulse) may reach the necessary forces and acceleration (increase will have to be very large, 100 enp-1000 ENP). The particles of increased energy can be achieved with the circular accelerators and linear or modern. The particles increased energy will be great and, in addition, will have to grow and flow of the accelerated particle (and the diameter of the manufacturer, where one increase enough flow, the energy required will be $10 \mathrm{GeV}-10 \mathrm{TeV})$.

The immediate consequence of all the higher power consumption of the particles will be increasing the speed and autonomy of the ship. Now we can achieve high speeds in a very short time. Ship will pass through any atmosphere (including water), with ease. The ship can take off or landed directly.

Initially, can be used to deliver the old forms (with old design), which shall be adapted and the accelerator.

\section{Acknowledgement}

The work was appreciated by teams of professors from the departments of automobiles from several universities in Romania and Italy. This text was acknowledged and appreciated by Associate Professor Aniello Riccio SECONDA UNIVERSITA' DEGLI STUDI DI NAPOLI Italy, whom we thanks and in this way.

\section{Funding Information}

Research contract: Contract number 36-5-4D/1986 from 24IV1985, beneficiary CNST RO (Romanian National Center for Science and Technology) Improving dynamic mechanisms internal combustion engines. All these matters are copyrighted. Copyrights: 548cgiywDssin, from: 22-04-2010, 08:48:48.

\section{Author's Contributions}

All the authors contributed equally to prepare, develop and carry out this manuscript.

\section{Ethics}

Authors declare that are not ethical issues that may arise after the publication of this manuscript. This article is original and contains unpublished material.

\section{References}

Aversa, R., R.V.V. Petrescu, A. Apicella and F.I.T. Petrescu, 2017a. Nano-diamond hybrid materials for structural biomedical application. Am. J. Biochem. Biotechnol.

Aversa, R., R.V. Petrescu, B. Akash, R.B. Bucinell and J.M. Corchado et al., 2017b. Kinematics and forces to a new model forging manipulator. Am. J. Applied Sci., 14: 60-80.

Aversa, R., R.V. Petrescu, A. Apicella, F.I.T. Petrescu and J.K. Calautit et al., 2017c. Something about the $\mathrm{V}$ engines design. Am. J. Applied Sci., 14: 34-52.

Aversa, R., D. Parcesepe, R.V.V. Petrescu, F. Berto and G. Chen et al., 2017d. Processability of bulk metallic glasses. Am. J. Applied Sci., 14: 294-301.

Aversa, R., R.V.V. Petrescu, B. Akash, R.B. Bucinell and J.M. Corchado et al., 2017e. Something about the balancing of thermal motors. Am. J. Eng. Applied Sci., 10: 200-217. DOI: 10.3844/ajeassp.2017.200.217

Aversa, R., F.I.T. Petrescu, R.V. Petrescu and A. Apicella, 2016a. Biomimetic FEA bone modeling for customized hybrid biological prostheses development. Am. J. Applied Sci., 13: 1060-1067. DOI: 10.3844/ajassp.2016.1060.1067

Aversa, R., D. Parcesepe, R.V. Petrescu, G. Chen and F.I.T. Petrescu et al., 2016b. Glassy amorphous metal injection molded induced morphological defects. Am. J. Applied Sci. 13: 1476-1482. 
Aversa, R., R.V. Petrescu, F.I.T. Petrescu and A. Apicella, 2016c. Smart-factory: Optimization and process control of composite centrifuged pipes. Am. J. Applied Sci., 13: 1330-1341.

Aversa, R., F. Tamburrino, R.V. Petrescu, F.I.T. Petrescu and M. Artur et al., 2016d. Biomechanically inspired shape memory effect machines driven by muscle like acting NiTi alloys. Am. J. Applied Sci., 13: 1264-1271.

Aversa, R., E.M. Buzea, R.V. Petrescu, A. Apicella and M. Neacsa et al., 2016e. Present a mechatronic system having able to determine the concentration of carotenoids. Am. J. Eng. Applied Sci., 9: 1106-1111.

Aversa, R., R.V. Petrescu, R. Sorrentino, F.I.T. Petrescu and A. Apicella, 2016f. Hybrid ceramo-polymeric nanocomposite for biomimetic scaffolds design and preparation. Am. J. Eng. Applied Sci., 9: 1096-1105.

Aversa, R., V. Perrotta, R.V. Petrescu, C. Misiano and F.I.T. Petrescu et al., 2016g. From structural colors to super-hydrophobicity and achromatic transparent protective coatings: Ion plating plasma assisted $\mathrm{TiO}_{2}$ and $\mathrm{SiO}_{2}$ nano-film deposition. Am. J. Eng. Applied Sci., 9: 1037-1045.

Aversa, R., R.V. Petrescu, F.I.T. Petrescu and A. Apicella, 2016h. Biomimetic and evolutionary design driven innovation in sustainable products development. Am. J. Eng. Applied Sci., 9: 1027-1036.

Aversa, R., R.V. Petrescu, A. Apicella and F.I.T. Petrescu, 2016i. Mitochondria are naturally micro robots-a review. Am. J. Eng. Applied Sci., 9: 991-1002.

Aversa, R., R.V. Petrescu, A. Apicella and F.I.T. Petrescu, 2016j. We are addicted to vitamins $\mathrm{C}$ and E-A review. Am. J. Eng. Applied Sci., 9: 1003-1018.

Aversa, R., R.V. Petrescu, A. Apicella and F.I.T. Petrescu, 2016k. Physiologic human fluids and swelling behavior of hydrophilic biocompatible hybrid ceramo-polymeric materials. Am. J. Eng. Applied Sci., 9: 962-972.

Aversa, R., R.V. Petrescu, A. Apicella and F.I.T. Petrescu, 20161. One can slow down the aging through antioxidants. Am. J. Eng. Applied Sci., 9: 1112-1126.
Aversa, R., R.V. Petrescu, A. Apicella and F.I.T. Petrescu, 2016m. About homeopathy or «similia similibus curentur 》. Am. J. Eng. Applied Sci., 9: 1164-1172.

Aversa, R., R.V. Petrescu, A. Apicella, F.I.T. Petrescu, 2016n. The basic elements of life's. Am. J. Eng. Applied Sci., 9: 1189-1197.

Aversa, R., F.I.T. Petrescu, R.V. Petrescu and A. Apicella, 2016o. Flexible stem trabecular prostheses. Am. J. Eng. Applied Sci., 9: 1213-1221.

Goddard, 1916. Rocket apparatus patent december 15, 1916. Smithsonian Institution Archives.

Kaufman, H.R., 1959. Installations at NASA Glenn.

Oberth, H., 1955. They come from outer space. Fly. Saucer Rev., 1: 12-14.

Hermann Oberth, From Wikipedia, the free encyclopedia.

https://en.wikipedia.org/wiki/Hermann_Oberth

Petrescu, R.V. and F.I. Petrescu, 2013a. Lockheed Martin. 1st Edn., CreateSpace, pp: 114.

Petrescu, R.V. and F.I. Petrescu, 2013b. Northrop. 1st Edn., CreateSpace, pp: 96.

Petrescu, R.V. and F.I. Petrescu, 2013c. The Aviation History or New Aircraft I Color. 1st Edn., CreateSpace, pp: 292.

Petrescu, F.I. and R.V. Petrescu, 2012. New Aircraft II. 1st Edn., Books On Demand, pp: 138.

Petrescu, F.I. and R.V. Petrescu, 2011. Memories About Flight. 1st Edn., CreateSpace, pp: 652.

Petrescu, F.I.T., 2009. New aircraft. Proceedings of the 3rd International Conference on Computational Mechanics, Oct. 29-30, Brasov, Romania.

Petrescu, F.I.T., A. Apicella, R.V.V. Petrescu, S.P. Kozaitis and R.B. Bucinell et al., 2016. Environmental protection through nuclear energy. Am. J. Applied Sci., 13: 941-946.

Petrescu, F.I.T. and J.K. Calautit, 2016. About nano fusion and dynamic fusion. Am. J. Applied Sci., 13: 261-266. 